\title{
RELAÇÕES FEDERATIVAS NAS POLÍTICAS SOCIAIS
}

\author{
MARTA ARReTCHE*
}

\begin{abstract}
RESUMO: O artigo apresenta os conceitos de Estado federativo e descentralização, demonstrando suas distinções. Mostra que, no Brasil, a restauração do federalismo, no final dos anos 80 , ocorreu anteriormente à descentralização das políticas sociais, no final dos anos 90. Demonstra também que, no tocante à descentralização das políticas sociais, a trajetória do Brasil guarda semelhanças com as relações federativas nos EUA, em virtude da baixa centralidade das políticas sociais na agenda dos governos locais.
\end{abstract}

Palavras-chave: Estado federativo. Políticas sociais. Descentralização.

\section{Federal States and social policies}

ABSTRACT: Through the analysis of the concepts of Federal States and decentralization, this paper aims at demonstrating the distinctions between both. It shows that, in Brazil, federalism was reinstated in the late 1980 s, prior to the social policies decentralization, in the late 1990s. It pinpoints that, owing to the lack of importance of social policies in local administrations, Brazil presents a decentralization pattern similar to that of North-America.

Key words: Federal States. Social Policies. Decentralization

Professora de Ciência Política da Universidade Estadual Paulista (Unesp/Araraquara); doutora em Ciências Sociais pelo Instituto de Filosofia e Ciências Sociais (IFCH) da Universidade Estadual de Campinas (UNICAMP); pós-doutora no Massachusetts Institute of Technology (MIT) em (Boston).E-mail: arretche@uol.com.br

Educ. Soc., Campinas, v. 23, n. 80 , setembro/2002, p. 25-48

Disponível em <http://www.cedes.unicamp.br> 

e 1980 consistia na descentralização das políticas públicas. A avaliação unânime de que a excessiva centralização decisória do regime militar havia produzido ineficiência, corrupção e ausência de participação no processo decisório conduziu a um grande consenso - que reunia, na verdade, correntes políticas à esquerda e à direita - em torno das virtudes da descentralização. Esta última esperava-se - produziria eficiência, participação, transparência, accountability, entre outras virtudes esperadas da gestão pública. Assim, no Brasil dos anos de 1980, centralização e autoritarismo eram ambos encarados como filhos da ditadura, ao passo que descentralização, democratização do processo decisório e eficiência na gestão pública andariam automaticamente juntas.

Este debate não se restringia ao Brasil. Também em países com democracias estáveis, a descentralização aparecia como uma alternativa às estruturas decisórias centralizadas instituídas durante a construção dos Estados de Bem-Estar Social, de inspiração keynesiana. Em alguns países europeus, como a França, esperava-se que a descentralização operasse como um instrumento de radicalização democrática, com vistas à ampliação dos canais de participação política (Rosanvallon, 1993). Em outros países, como a Itália, a descentralização era portadora de expectativas relacionadas à vitalização dos governos regionais, esvaziados em seus poderes por Estados unitários excessivamente centralizados (Putnam, 1996). Em outros países ainda, como Bélgica e Espanha, a grande demanda era a do federalismo, isto é, a afirmação da autonomia política de etnias sub-representadas politicamente em Estados unitários com regras eleitorais majoritárias (Watts, 1999).

$\mathrm{Na}$ esteira destes debates, alguns países permaneceram Estados unitários e adotaram programas extensivos de descentralização, como foram os casos da França e da Itália (D’Arcy e Baena del Alcazar, 1986; Putnam, 1996). O Reino Unido devolveu certas prerrogativas a Escócia, País de Gales e Irlanda (Watts, 1999). Em outros casos, entretanto, imperaram as soluções políticas federativas. Bélgica (1993), África do Sul (1996), Espanha (a partir de 1978) adotaram sistemas plena ou parcialmente federativos. No norte da Itália, há forte pressão pela adoção do federalismo. Grande parte do processo de integração da União Européia está baseada em princípios federativos (Watts, 1999).

No Brasil, ocorreram os dois fenômenos. Reformas das instituições políticas ao longo dos anos de 1980 - particularmente, a retoma- 
da de eleições diretas em todos os níveis de governo a partir de 1982 e as deliberações da Constituição Federal de 1988 - recuperaram as bases federativas do Estado brasileiro, suprimidas durante a ditadura militar. Posteriormente - já nos anos de 1990 e já completada a institucionalização do Estado federativo - implementou-se um extensivo programa de descentralização, particularmente na área das políticas sociais. A simultaneidade histórica dos dois processos tem deixado a falsa impressão de que estes são a mesma coisa, quando não o são. Embora originários do mesmo processo histórico no Brasil - a negação do autoritarismo e da centralização -, federalismo e descentralização não implicam engenharias políticas gêmeas.

Paralelamente à onda de surgimento de novas federações, ressurgiu o interesse acadêmico pelo estudo das federaçóes. As análises contemporâneas, particularmente os estudos em ciência política dos anos de 1980 e 1990, convergem quanto à interpretação da capacidade governativa em Estados federativos: consideram que a engenharia institucional das federações tenderia a restringir o potencial de implementação de reformas. Em essência, os estudos comparados sobre federalismo argumentam que a dispersão de poder, típica desse tipo de Estado, aumenta exponencialmente as dificuldades para a adoção de reformas abrangentes. Entretanto, no caso brasileiro, a implementação de um abrangente programa de descentralização das políticas sociais a partir de meados dos anos de 1990, que transferiu para os estados e municípios brasileiros grande parte das funções de gestão de políticas sociais, não confirma as previsões que apontam para a virtual paralisia decisória em Estados federativos.

Este artigo discutirá os conceitos de federalismo e descentralização, de modo que se clarifiquem suas distinçōes e, em seguida, apresentará as previsões da literatura sobre os resultados esperados da capacidade governativa em Estados federativos. Na segunda parte, o artigo apresentará a extensão do processo de descentralização das políticas sociais no Brasil. Na parte final, apresentará uma tentativa de explicação para o aparente paradoxo entre federalismo e descentralização no Brasil.

\section{Federalismo e descentralização}

A distinção entre Estados federativos e unitários diz respeito às formas de distribuição da autoridade política dos Estados nacionais. Estados federativos são uma forma particular de governo dividido 
verticalmente, de tal modo que diferentes níveis de governo têm autoridade sobre a mesma população e território (Lijphart, 1999). Nesses Estados, o governo central e os governos locais são independentes entre si e soberanos em suas respectivas jurisdições (Riker, 1987), pois cada governo local - cuja jurisdição pode variar, conforme assim o definir a Constituição - está resguardado pelo princípio da soberania, o que significa que estes são atores políticos autônomos com capacidade para implementar (pelo menos, algumas de) suas próprias políticas (Pierson \& Leibfried, 1995, p. 20). A soberania dos governos locais deriva do voto popular direto, da autonomia de suas bases fiscais e, em muitos casos, de uma força militar própria. Além disso, as unidades componentes da federação têm uma câmara de representação territorial no plano federal - a Câmara Alta ou Senado -, cuja autoridade legislativa varia entre as federações (Lijphart, 1999). ${ }^{1}$

Nos Estados unitários, apenas o governo central tem autoridade política própria, derivada do voto popular direto. A unidade do Estado nacional está garantida pela concentração de autoridade política, fiscal e militar no governo central, ao passo que a autoridade política dos governos locais é derivada de uma delegação de autoridade da autoridade política central. Em tese, portanto, a autonomia dos governos locais é mais reduzida nos Estados unitários do que nos federativos.

Observe-se, portanto, que a concentração da autoridade política e fiscal no governo central é uma forma de distribuição vertical da autoridade política que não esteve em contradição com a construção dos Estados nacionais democráticos do ocidente europeu. A associação entre autoritarismo e centralização fez parte da trajetória histórica no Brasil, assim como de grande parte dos países latino-americanos.

Durante o regime militar, as relações intergovernamentais do Estado brasileiro eram na prática muito mais próximas às formas que caracterizam um Estado unitário que àquelas que caracterizam as federações. Governadores e prefeitos das capitais e de cerca de 150 cidades de médio e grande porte não tinham autonomia política, pois eram selecionados, de fato, mediante indicação da cúpula militar, isto é, sua autoridade política não derivava do voto popular direto. Além disso, governadores e prefeitos detinham escassa autonomia fiscal, pois a centralização instituída pela reforma fiscal dos anos de 1960 concentrou os principais tributos nas mãos do 
governo federal. Finalmente, os governadores não tinham autoridade sobre suas bases militares, uma vez que as polícias militares estaduais foram colocadas sob controle do Exército Nacional.

Ao longo dos anos de 1980, recuperaram-se as bases do Estado federativo no Brasil. A democratização - particularmente a retomada de eleições diretas para todos os níveis de governo - e a descentralização fiscal da Constituição de 1988 alteraram profundamente as bases de autoridade dos governos locais. A autoridade política de governadores e prefeitos voltou a ser baseada no voto popular direto. Paralelamente, estes últimos também expandiram expressivamente sua autoridade sobre recursos fiscais - uma vez que se ampliou a parcela dos tributos federais que é automaticamente transferida aos governos subnacionais -, assim como passaram a ter autoridade tributária sobre impostos de significativa importância.

A descentralização, por sua vez, diz respeito à distribuição das funçōes administrativas entre os nivveis de governo (Riker, 1987). Formas as mais variadas de transferência de recursos e delegação de funções permitem que um dado nível de governo desempenhe funçôes de gestão de uma dada política, independentemente de sua autonomia política e fiscal.

Lijphart (1999) demonstra que, nos dias atuais, a maior parte dos Estados federativos também é descentralizada, mas Riker (1975) demonstrou que o grau de centralização na distribuição de competências administrativas variou muito ao longo da história dos países federativos, sem que isso tenha alterado substancialmente o que é a característica essencial do federalismo, isto é, a autonomia política dos governos locais.

O Reino Unido, por exemplo, é um Estado unitário cujas instituições políticas concentram a autoridade política no governo central: concentra poderes no executivo central; os poderes legislativo e executivo estão fundidos, com preponderância do executivo; a Câmara Baixa tem extensos poderes legislativos, ao passo que a Câmara Alta tem poderes reduzidos; a eleição ocorre por singlemembre districts; os governos locais operam como executores das políticas centrais, sem autonomia fiscal; o Parlamento (Câmara Baixa) é a suprema autoridade no processo de definição das leis; o poder judiciário não tem poder de revisão das decisōes parlamentares, com base em uma Constituição previamente aprovada, à qual o Parlamento deveria estar submetido; não há espaço para decisōes baseadas na democracia direta, como plebiscitos (Lijphart, 1984). Entretanto, 
do ponto de vista da distribuição de competências, a gestão de políticas públicas é extensamente descentralizada no Reino Unido.

No início dos anos de 1990 no Brasil, por sua vez, as instituições políticas federativas já estavam plenamente instauradas, ao passo que a gestão de políticas públicas - particularmente na área social - continuava centralizada, isto é, o governo federal - em virtude do legado do regime militar - continuava responsável pela gestão e pelo financiamento das políticas de saúde, habitação, merenda escolar, livro didático, assistência social etc.

\section{Federalismo e capacidade governativa}

A literatura sobre federalismo dos anos de 1980 e 1990 dedicou-se a analisar o impacto do federalismo sobre a autoridade dos governos centrais, particularmente sua capacidade de mudar o status quo, isto é, produzir inovaçōes e implementar reformas de políticas. Teoricamente, essa literatura apresenta um razoável grau de consenso em torno da seguinte proposição: Estados federativos tendem a restringir as possibilidades de mudança, porque a autonomia dos governos locais opera no sentido de dispersar o exercício da autoridade política, aumentando o poder de veto das minorias (Lijphart, 1984) ou, ainda, porque a presença de um maior número de veto players institucionalizados nas arenas decisórias aumenta o potencial de estabilidade das políticas existentes (Tsebelis, 1997). Sistemas federativos restringem o potencial de mudanças de políticas porque as garantias institucionais dos Estados-membros no processo decisório tendem a produzir decisões políticas com base no "mínimo denominador comum" (Pierson \& Leibfried, 1995).

A maior parte das lições que extraímos da análise de sistemas presidenciais e parlamentares pode ser igualmente aplicada a fatores de terceiro nível (third-tier), tais como o federalismo. Tal como os sistemas parlamentares, federalismo é uma designação genérica que mascara uma variedade de arranjos institucionais que criam riscos e oportunidades distintos para as capacidades de governo. Governos provinciais e federais podem ter autoridade para intervir em uma área de política sem permissão do outro nível de governo. Isso tende a prover fortes incentivos para a inovação em políticas públicas na medida em que cada nível de governo tenta controlar a jurisdição de uma política antes que o outro o faça. Entretanto, esse tipo de federalismo também corre o risco de que os diferentes níveis de governo tenderão a impor conflitos entre programas, elevação dos custos da implementação e tornarão o problema da coordenação de objetivos ainda mais 
difícil. Alternativamente, o federalismo pode ser estruturado de modo a requerer a aprovação dos governos subnacionais afetados e do governo federal para qualquer desvio do status quo. Estes arranjos (...) acrescentam pontos de veto e inibem a implementaçãa. (Weaver \& Rockman, 1993, p. 459)

Em outras palavras, em Estados federativos a implementação de reformas de âmbito nacional tenderia a ser mais difícil do que em Estados unitários, porque os governos locais têm incentivos e recursos para implementar as suas próprias políticas independentemente do governo federal, porque têm representação no Parlamento para vetar as iniciativas de política que são contrárias a seus interesses ou, ainda, porque podem simplesmente não aderir à implementação de programas do governo federal.

A lentidão do processo de descentralização das políticas sociais no Brasil até meados dos anos de 1990 (Almeida, 1995) poderia nos levar a acreditar que esta foi expressão da capacidade de veto dos governos locais, pois há diversas razóes para crer que, de fato, estes - tomados em seu conjunto - resistiam a assumir a responsabilidade pela gestão das políticas sociais e pretendiam preservar sua autonomia para gastar os recursos recém-adquiridos com a descentralização fiscal (Arretche, 2000). No entanto, a capacidade do Governo Fernando Henrique Cardoso para implementar reformas das políticas sociais mostra que os governos locais não foram capazes de vetar um extensivo programa pelo qual muitas funções de gestão lhes foram transferidas.

\section{A descentralização das políticas sociais no Brasil}

No Governo Fernando Henrique Cardoso, foi significativamente alterada a distribuição de competências entre municípios, estados e governo federal para a provisão de serviços sociais. Das 44 companhias municipais criadas pelo BNH, 12 fecharam e mais de 20 redirecionaram suas atividades para a área de desenvolvimento urbano. A política social de habitação deixou de ser dominantemente produzida por intermédio de companhias municipais de habitação e passou a operar segundo linhas de crédito ao mutuário final. Abriu-se uma onda de privatizações das companhias estaduais de saneamento. Em conjunto, essas mudanças apontam para a desestatização dos serviços habitacionais e de saneamento. Além disso, a totalidade dos serviços de atenção básica foi transferida para os municípios, assim como se operou uma significativa municipalização da oferta de matrículas no ensino fundamental. 
Em conjunto, essas mudanças implicam expressiva transferência de funçôes de gestão para os municípios.

\section{Mudança no paradigma das políticas de habitação e saneamento}

Nas áreas de habitação e saneamento, ocorreu uma mudança do paradigma de política pública do regime militar para o Governo Fernando Henrique Cardoso. Nenhum dos governos democráticos anteriores tinha uma agenda de reformas que visasse a modificar radicalmente o modelo de política anterior.

Quer para a política de habitação social, quer para o saneamento básico, o modelo do regime militar era simultaneamente estatal e centralizado. A oferta de bens e serviços fazia-se via produção pública a habitação social e os serviços de saneamento básico eram geridos por empresas estatais. No plano federal, havia uma agência que centralizava a formulação dos programas e a arrecadação da principal fonte de financiamento da política: um fundo compulsório pago pelas empresas com base na folha de salários do mercado formal de trabalho - o FGTS. Com base nesse modelo, constitui-se no país uma rede de 44 empresas públicas municipais e estaduais de habitação social, assim como 27 companhias estaduais de saneamento. Por efeito não desejado da política anterior, existem ainda centenas de companhias municipais de saneamento, concentradas particularmente nas regiōes Sul e Sudeste.

A agenda de reformas do Governo Fernando Henrique Cardoso objetivou rever esse paradigma: descentralizar a alocação dos recursos federais e introduzir princípios de mercado para a provisão de serviços. Com relação a este último, a política visou a abrir espaço para a participação do setor privado na provisão de serviços e introduzir uma política de crédito ao mutuário final.

O programa de reformas derivou de uma avaliação negativa dos resultados do modelo anterior. O novo governo avaliava que a corrupção e ineficiência administrativas dos governos civis anteriores foram possíveis graças à centralização federal; por conseguinte, era forte a concepção, derivada desta primeira, que associava positivamente descentralização a formas mais ágeis, democráticas e eficientes de gestão. A defesa da descentralização era reforçada por uma avaliação de que a burocracia federal estava viciada pelos padrōes administrativos prévios, o que implicaria que, se esta fosse instituída de poder para alocar centralizadamente os recursos do FGTS, dificilmente a corrupção seria abolida. 
Além disso, a nova equipe de governo avaliava que o modelo anterior gerava incentivos à ineficiência das prestadoras estaduais e municipais. Políticas tarifárias voltadas a satisfazer o eleitorado, renegociação sistemática das dívidas com o governo federal, empreguismo e uma burocracia ativa na defesa de seus próprios interesses eram o resultado do modelo anterior. A separação entre regulação (estatal) e provisão (privada ou pública com padrōes privados de eficiência) seria a alternativa mais adequada.

Por fim, na política social de habitação, o financiamento à produção, do modelo anterior, implicava que o credito hipotecário só pudesse ser obtido para imóveis cuja produção tivesse sido executada pelas companhias municipais de habitação. Como nesse modelo não é o mutuário que tem um financiamento - e sim o imóvel que será objeto da compra -, sua conseqüência direta é a reduzida margem de escolha do mutuário final no mercado imobiliário, assim como a impossibilidade de ativar o mercado de imóveis usados. O financiamento direto ao mutuário final, habilitando-o a adquirir um imóvel diretamente no mercado, era uma das principais críticas - inclusive de setores da esquerda - ao modelo anterior.

O Governo Fernando Henrique Cardoso, já no seu primeiro mandato, obteve um razoável grau de sucesso na implementação desta agenda. Sua estratégia combinou uma radical mudança nas regras de transferência de recursos, associada ao desfinanciamento das empresas estaduais e municipais.

Já no primeiro ano de governo, os governadores de estado foram contemplados com a possibilidade de ter grande autoridade sobre a alocação de suas respectivas parcelas do fundo público federal para o desenvolvimento urbano, o FGTS. ${ }^{2}$ Para aderir ao programa federal, os governadores deveriam constituir comissōes estaduais, com representação paritária entre governo do estado, governos municipais e sociedade civil. Os governadores contavam com grande autonomia na composição dessas comissões, o que permitiu um comportamento generalizado de montagem de comissōes passíveis de controle no processo decisório de seleção de projetos.

$\mathrm{Na}$ história das políticas públicas no Brasil, este deve estar entre os programas com maior velocidade de implantaçãa: em apenas quatro meses, todos os estados brasileiros haviam aderido ao programa. $\mathrm{Na}$ base deste sucesso estão as regras de operação do programa: a definição de uma estrutura de incentivos que tornaram extremamente atraente a adesão dos governadores ao programa federal de descentralização. 
A descentralização da autoridade para alocação desses recursos, entretanto, foi combinada com um endurecimento das exigências para a obtenção dos empréstimos federais. Mesmo que aprovada pela comissão estadual, uma empresa pública estadual ou municipal - ou mesmo um governo estadual ou municipal - somente poderia receber um financiamento caso comprovasse capacidade de endividamento. Assim, no quadro de endividamento generalizado de meados dos anos de 1990, somente aquelas empresas públicas que tivessem sucesso nas medidas de saneamento de suas finanças obteriam os empréstimos federais.

Essa medida dividia os governadores - entre aqueles que "estavam fazendo a sua lição de casa" e aqueles que resistiam a adotar medidas de contenção do déficit público -, bem como criava incentivos para a reestruturação das empresas públicas de habitação e saneamento. Empresas públicas já excessivamente endividadas com o governo federal - que tinha sido de longe o maior emprestador até então - passaram a ser objeto de uma política de desfinanciamento.

No debate público, o governo federal argumentava que o fundo público federal, baseado na folha de salários e destinado também a indenizar trabalhadores demitidos sem justa causa, vinha sendo penalizado pelo desemprego e pelo baixo nível dos salários. O caráter pró-cíclico da fonte de recursos herdada do modelo anterior erodia a capacidade de o governo federal atingir a meta da universalização dos serviços exclusivamente com base em recursos públicos. Para isso, seria necessário atrair recursos do setor privado, abrindo as empresas estatais - particularmente as de saneamento - a formas de terceirização e privatização dos serviços.

No plano da implementação, entretanto, em razão do endurecimento das condições de empréstimo e da política de desfinanciamento, acumulava-se um saldo muito elevado de recursos do FGTS não aplicados. No terceiro ano do primeiro mandato do presidente Fernando Henrique Cardoso, esse saldo era de $\mathrm{R} \$ 9,5$ bilhōes (Pinheiro, 1998), algo equivalente a mais da metade da arrecadação bruta anual do Fundo nos anos de 1996 e 1997.

Paralelamente, dois bancos federais de fomento abriram linhas de crédito para financiar as privatizações na área de saneamento. $\mathrm{O}$ BNDES financiou algumas das privatizaçôes municipais e adiantou recursos para a privatização de uma companhia estadual e a CEF foi autorizada, em 1997, pelo Conselho Curador do FGTS, a criar um programa pelo qual os recursos do FGTS poderiam ser utilizados para financiar as privatizações das companhias de saneamento. 
$\mathrm{Na}$ área de habitação, entre 1995 e 2000, 12 das 44 COHABS declararam falência ou diversificaram suas atividades, passando a operar como institutos de desenvolvimento urbano e não mais como agência de promoção pública de habitaçóes para baixa renda. ${ }^{3}$

$\mathrm{Na}$ área de saneamento, a privatização das empresas estaduais era uma alternativa atraente para alguns governadores de estado e prefeitos municipais. Alguns compartilhavam da mesma avaliação negativa do governo federal em relação à prestação pública de serviços, especialmente pelo fato de que estas empresas tinham dado existência a burocracias autônomas e politicamente ativas sobre as quais a autoridade política tinha reduzido poder de controle. Outros, premidos por problemas fiscais, viam na venda de suas empresas uma alternativa seja para reduzir o déficit público, seja para arrecadar recursos que poderiam ser empregados com maior liberdade alocativa. Inicia-se, assim, na segunda metade dos anos de 1990, uma onda de tentativas de privatização de companhias municipais e estaduais de saneamento.

$\mathrm{Na}$ área de habitação social, o governo federal criou, já no primeiro ano de governo, duas linhas de financiamento. A primeira, o Programa Pró-Moradia, pode ser considerada uma continuidade do modelo instalado pelo antigo BNH. Voltado para a população de até três salários mínimos, contaria com a intermediação de agentes promotores públicos, prefeituras e órgãos da administração direta e indireta para a construção ou melhoria de unidades habitacionais novas ou para a execução de modalidades diversas de infra-estrutura urbana.

$\mathrm{O}$ desenho institucional da segunda linha de financiamento, por sua vez, o Programa Carta de Crédito Individual, rompia com o paradigma do modelo anterior. Voltado à população de até 12 salários mínimos, deveria conceder financiamentos diretamente ao mutuário final para que este pudesse adquirir uma unidade habitacional nova ou usada, ou mesmo construir ou reformar sua própria unidade habitacional. Tratava-se de um programa de financiamento à demanda habitacional, cuja principal característica é permitir ao mutuário adquirir um imóvel diretamente no mercado imobiliário.

Entre 1995-1998, o Programa Pró-Moradia, isto é, a rede de empresas públicas de habitação, recebeu $11,5 \%$ dos recursos habitacionais do FGTS, via Programa Pró-Moradia, e 28\% dos recursos destinados ao Programa Carta de Crédito Associativo. O Programa Carta de Crédito Individual, por sua vez, recebeu 76\% desses recursos, os quais foram utilizados majoritariamente para a aquisição de imóveis usados (Tabelas 1, 2 e 3). 


\section{Tabela 1}

Distribuição dos Recursos do FGTS por Programa Habitacional $1995 / 1998$

\begin{tabular}{lcc} 
& \multicolumn{3}{c}{$(\mathrm{em} \mathrm{R} \$ 1.000)$} & \\
\hline Programa & Valor contratado & $\%$ do total \\
\hline Pró-Moradia & 772.953 & 11,41 \\
\hline Carta de Crédito Individual & 5.136 .520 & 75,80 \\
\hline Carta de Crédito Associativo & 821.207 & 12,12 \\
\hline Apoio à Produção & 45.197 & 0,67 \\
\hline Total & 6.775 .877 & 100 \\
\hline
\end{tabular}

Fonte: Base de Dados da Caixa Econômica Federal - 30/06/1999

Extraído de: USP/EESC/FIPAL, 2000.

\section{Tabela 2}

Programa Carta de Crédito Individual Valores Contratados Globais por Modalidade 1995-1998

$$
(\mathrm{em} \mathrm{R} \$ 1,00)
$$

\begin{tabular}{lcc}
\hline Modalidades & $\$$ & $\%$ \\
\hline Ampliação & $48.944,00$ & $1 \%$ \\
\hline Lotes & $55.856,00$ & $1 \%$ \\
\hline Conclusão & $27.741,00$ & $1 \%$ \\
\hline Construção & $311.325,00$ & $6 \%$ \\
\hline Cesta & $347.259,00$ & $7 \%$ \\
\hline Usado & $3.486 .910,00$ & $68 \%$ \\
\hline Novo & $352.402,00$ & $7 \%$ \\
\hline Terr+const & $504.798,00$ & $10 \%$ \\
\hline Remanesc & $1.279,00$ & $0 \%$ \\
\hline TOTAL & $5.136 .514,00$ & $100 \%$ \\
\hline
\end{tabular}

Fonte: USP/EESC/FIPAL, 2000. 


\section{Tabela 3}

Programa Carta de Crédito Associativo

Distribuição das Contratações por Tipo de Agente Promotor

Brasil - 1995/1998

$(\mathrm{R} \$$ mil $)$

\begin{tabular}{lrrrr}
\hline \multicolumn{1}{c}{ Promotor } & Valor do empréstimo & \multicolumn{1}{c}{$\%$} & No unidades & \multicolumn{1}{c}{$\%$} \\
\hline Total & 821.207 & $100 \%$ & 53.748 & $100 \%$ \\
\hline Ccred Cohab & 173.233 & $21 \%$ & 15.155 & $28 \%$ \\
\hline Ccred Entid & 647.974 & $79 \%$ & 38.593 & $72 \%$ \\
\hline
\end{tabular}

Fonte: USP/EESC/FIPAL, 2000.

Portanto, via gestão seletiva das linhas de crédito, ocorreu uma inflexão significativa na política habitacional do governo federal: de um modelo de política habitacional centrado no financiamento à produção de habitaçóes novas e assentado em uma rede de prestadoras públicas para um modelo de política habitacional centrado no financiamento ao mutuário final e, particularmente, destinado à aquisição de imóveis usados.

A alteração radical do modelo de financiamento à aquisição da casa própria contava ainda com o apoio dos mutuários, pois a nova modalidade - uma antiga reivindicação de diversos críticos do modelo anterior - ampliou significativamente a liberdade de escolha de unidades residenciais no mercado imobiliário. Desse modo, a estratégia de desfinanciamento e de gestão seletiva dos financiamentos habitacionais encontrava suporte político entre os potenciais beneficiários da política habitacional.

A gestão seletiva das linhas de financiamento não foi um resultado não-intencional, derivado da exigência de adimplência com o governo federal para obtenção de recursos do FGTS, isto é, o desfinanciamento das empresas públicas não foi resultado apenas das taxas de inadimplência das prestadoras públicas. A meta de prioridade de aplicação de recursos no Programa Carta de Crédito em detrimento do Programa Pró-Moradia foi objeto de uma Resolução do Conselho Curador do FGTs (no 246) já em 1996. Em outras palavras, o desfinanciamento das empresas públicas fez parte de uma estratégia cujo objetivo central era introduzir mecanismos de mercado na gestão das políticas de desenvolvimento urbano. 


\section{Municipalização do ensino fundamental}

Entre 1997 e 2000, ocorreu no Brasil uma significativa redistribuição das matrículas no nível fundamental de ensino. A matrícula total do setor público cresceu $6,7 \%$ no período, ao passo que as matrículas oferecidas pelos municípios cresceram $34,5 \%$ e as matrículas estaduais tiveram crescimento negativo $(-12,4 \%)$ (ver Tabela 4). Isso significa que ocorreu uma relevante transferência das matrículas até então oferecidas pelos governos estaduais para os governos municipais.

Este processo acelerado e numericamente significativo de municipalização das matrículas ocorreu a despeito de forte oposição dos governos municipais, particularmente da região Sudeste. Nesta, os governos estaduais (particularmente do estado de São Paulo) concentravam a oferta de matrículas no ensino fundamental.

A Constituição Federal de 1988 havia estabelecido que a oferta de matrículas no nível fundamental deveria ser universal e oferecida preferencialmente pelos governos municipais. Além disso, obrigava constitucionalmente governos estaduais e municipais a gastarem $25 \%$ de suas receitas de impostos e transferências em ensino. ${ }^{4}$ A obrigatoriedade de patamares de gasto deu origem a uma expansão generalizada - por parte de governos estaduais e municipais - da oferta de matrículas em todos os níveis de ensino - infantil, fundamental, médio e, até mesmo, superior.

Os ganhos fiscais dos municípios, derivados das regras de descentralização fiscal, associados à regra constitucional de vinculação de gasto com ensino - e, não com educação -, permitiram que a expansão do gasto municipal se direcionasse para outras atividades afins, tais como financiamento de bolsas de estudo, transporte escolar etc. Particularmente nas regiōes Sul e Sudeste, nas quais os governos estaduais já detinham uma participação importante na oferta de matrículas no ensino fundamental, a expansão de gasto dos municípios dirigiu-se fortemente para o ensino infantil.

O Ministério da Educação, no Governo Fernando Henrique Cardoso, tinha, entre outros itens de sua agenda de reformas, o objetivo de promover a municipalização e a valorização do ensino fundamental. A realização desses objetivos compreendia a prioridade ao ensino fundamental, mesmo que esta ocorresse em detrimento de outros níveis de ensino, assim como a valorização salarial de seus professores (vale dizer, daqueles que exercem diretamente atividades em sala de aula nesse nível de ensino). 

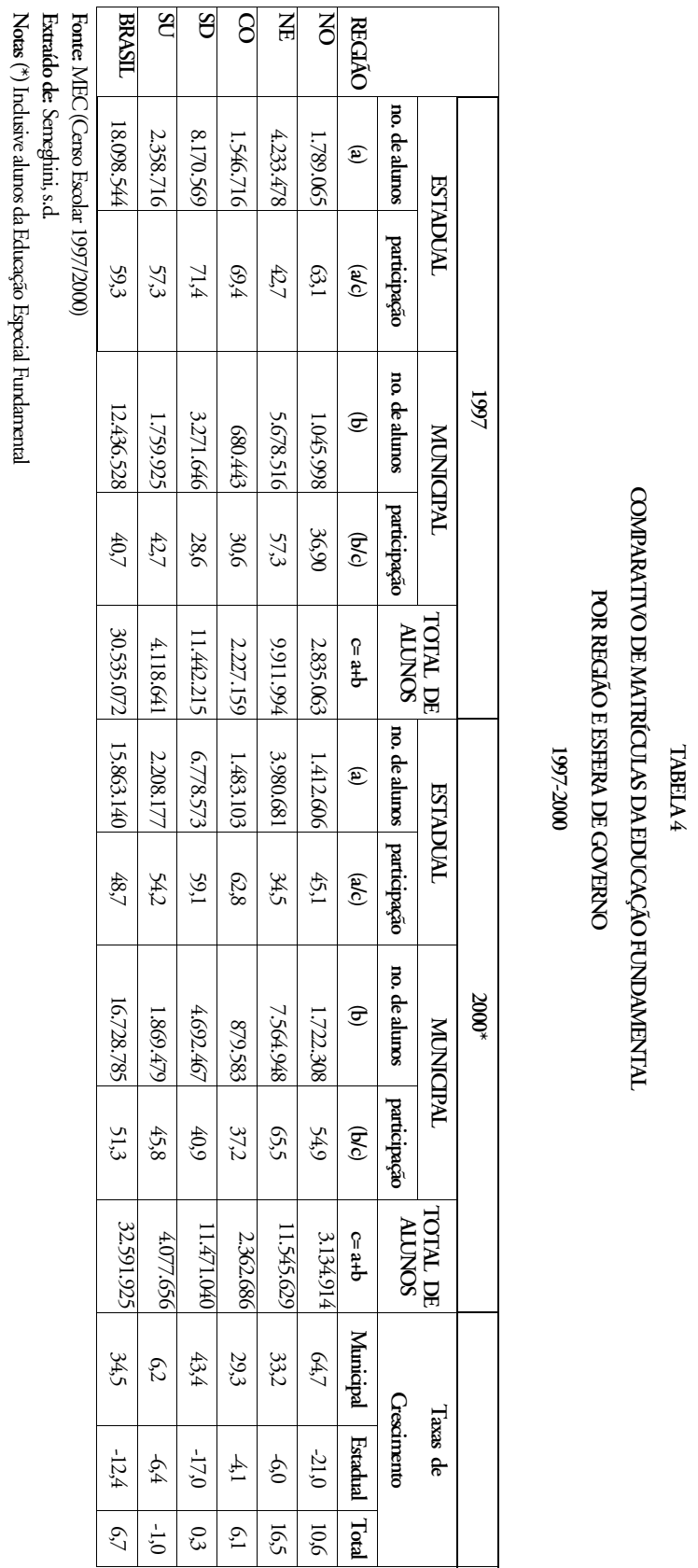

Educ. Soc., Campinas, v. 23, n. 80, setembro/2002, p. 25-48 
Para tal, a burocracia do Ministério elaborou um Projeto de Emenda Constitucional o qual previa que, pelo prazo de dez anos, estados e municípios deveriam aplicar, no mínimo, $15 \%$ de todas as suas receitas exclusivamente no ensino fundamental. Além disso, $60 \%$ destes recursos deveriam ser aplicados exclusivamente no pagamento de professores em efetivo exercício do magistério. Para garantir padrões mínimos de gasto em educação, a Emenda Constitucional também estabelece que deve ser estabelecido a cada ano um valor mínimo nacional de gasto por aluno. Esse valor seria complementado pelo governo federal nos estados em que o valor mínimo nacional não fosse alcançado.

$\mathrm{Na}$ prática, a implementação dessa Emenda Constitucional implica que, a cada ano, $15 \%$ das receitas de impostos de estados e municípios seriam contabilizados em um Fundo Estadual - o FUNDEF. ${ }^{5}$ As receitas desse Fundo são redistribuídas, em cada estado, entre governos estaduais e municipais proporcionalmente ao número de matrículas que cada unidade da federação oferece a cada ano.

A apresentação da proposta de Emenda Constitucional produziu forte oposição, particularmente dos governos municipais da região Sudeste. Na prática, ela significava que recursos já comprometidos com a manutenção do ensino infantil deveriam ser transferidos para os governos estaduais. A medida também provocou reação de governos estaduais, particularmente da região Nordeste e do Rio de Janeiro, onde a oferta de matrículas já era predominantemente municipal. Entretanto, a despeito da oposição organizada de parcela dos governos municipais e estaduais, a Emenda foi aprovada em dezembro de 1996, regulamentada em dezembro de 1996 e implementada a partir de 1998. É por esta razão que seu impacto se inicia posteriormente a 1997.

O acelerado processo de municipalização explica-se em grande parte pelo interesse dos municípios em aumentar suas receitas. Isto é, uma vez aprovada a Emenda Constitucional, a única estratégia possível para preservar as receitas municipais passou a ser aumentar a oferta de matrículas municipais na rede de ensino fundamental. A municipalização é, assim, o resultado da estrutura de incentivos da nova legislação sobre a decisão dos governos subnacionais.

O impacto sobre a situação docente também foi significativo. Pesquisa encomendada pelo MEC indica que ocorreu um crescimento global de $10 \%$ no número de professores e um aumento médio de $29,5 \%$ na remuneração dos professores. Na Região Nordeste, onde os 
salários dos professores eram muito baixos, a elevação média foi de 59,7\%. Na Região Norte, esse aumento foi de 35\% (Semeghini, s./d.).

À exceção de um programa de municipalização no Paraná, entre meados dos anos de 1980 e meados dos anos de 1990, e de alguns poucos esforços de municipalização no Nordeste durante o regime militar, as tentativas de municipalização por parte de governos estaduais tinham sido em geral fracassadas. Elas se defrontavam com as resistências dos governos municipais a assumir novas atribuições.

As novas regras constitucionais, portanto, conformam uma estrutura de incentivos que torna bastante atraente a oferta de matrículas no ensino fundamental, pois esta pode ser uma oportunidade para ganhos de receita combinada à ampliação da oferta de serviços à população e à elevação dos salários dos professores. Essa estrutura de incentivos explica em grande parte a acelerada municipalização das matrículas escolares.

\section{Descentralização da política de saúde}

Ao longo da década de 1990, o governo federal foi muito bemsucedido em transferir para os municípios brasileiros a responsabilidade pela gestão da atenção básica à saúde.

A descentralização e a universalização da política federal de saúde e a conseqüente construção do sus (Sistema Único de Saúde) passaram a ser normas constitucionais com a Constituição de 1988. Embora o princípio do direito universal de acesso aos serviços públicos de saúde passasse a ter validade imediatamente após a promulgação da Constituição, a municipalização dos serviços implicava um processo de reestruturação da estrutura nacional de organização dos serviços, cuja principal conseqüência seria a transferência de atividades até então desempenhadas pelo nível federal para os municípios. ${ }^{6} \mathrm{O}$ novo modelo estaria assentado na separação entre financiamento e provisão dos serviços (Costa et al., 1999), ficando o financiamento a cargo das três esferas de governo e a provisão dos serviços a cargo dos municípios.

A municipalização da gestão dos serviços foi o elemento central da agenda de reformas do governo federal na área da saúde ao longo da década de 1990 e pode-se afirmar que, deste ponto de vista, a reforma foi um sucesso. Em 2000, 99\% dos municípios estavam habilitados no Sistema Único de Saúde, aceitando assim as normas da política de descentralização do governo federal (ver Tabela 5). 


\section{Tabela 5}

Habilitação dos Municípios ao sus segundo anos selecionados Brasil - 1988-2000

\begin{tabular}{|l|c|c|c|c|}
\hline & 1988 & 1993 & 1996 & 2000 \\
\hline Municípios habilitados & Zero & 1074 & 3127 & 5450 \\
\hline Total de municípios & 4179 & 4974 & 4973 & 5507 \\
\hline Habilitados/Total (\%) & $0 \%$ & $26 \%$ & 62,87 & 98,96 \\
\hline
\end{tabular}

Fontes: Dados sobre Municipalização da saúde: Costa; Silva; Ribeiro, 1999; Guimarães, 2001. Dados sobre número de municípios: IBGE

A agenda da reforma tinha como objetivos universalizar o acesso aos serviços e descentralizar sua gestão, isto é, a reforma visou simultaneamente a romper com o modelo prévio assentado sobre o princípio contributivo e transferir aos municípios responsabilidades de gestão da prestação de serviços, mantendo a participação federal no financiamento da política. Tratava-se, portanto, de uma reforma que envolvia o princípio ordenador do direito à saúde e o modelo centralizado de prestação de serviços.

A universalização dos serviços implica ampliação do escopo de direitos dos cidadãos, uma vez que o princípio contributivo do modelo anterior excluía do acesso aos serviços camada significativa da população com baixos rendimentos ou formas precárias de inserção no mercado de trabalho. Este objetivo da reforma ampliar o escopo de beneficiários da política - seguramente representou um forte incentivo para a adesão dos municípios ao sus. Os créditos políticos derivados da ampliação da oferta de serviços de saúde criaram nas administraçóes locais incentivos para assumir sua gestão. ${ }^{7}$

No entanto, esta variável - o interesse das elites locais na visibilidade política da universalização dos serviços de saúde - não é suficiente para explicar a adesão dos municípios à política federal nem o ritmo em que esta ocorreu. $\mathrm{O}$ objetivo da universalização, a norma constitucional da municipalização dos serviços, a competição eleitoral e as condiçôes institucionais para a barganha federativa já estavam presentes no cenário político brasileiro em 1988. Estes fatores explicam, por exemplo, por que o número de estabelecimentos municipais de saúde tenha crescido de 2.961 para 18.662 
entre 1981 e 1992, passando de um porcentual de 22\% para $69 \%$ do total de estabelecimentos do setor público no mesmo período (Costa et al., 1999, p. 37).

No entanto, eles não explicam por que os municípios aceitaram a transferência da responsabilidade pela gestão dos serviços, tarefa razoavelmente mais complexa do que sua simples oferta, dada a distribuição desigual de capacidades estatais entre os diferentes níveis de governo. Essas variáveis também não são suficientes para explicar por que este processo de aceitação da transferência de responsabilidades se acelerou apenas na segunda metade dos anos de 1990 (ver Tabela 5).

A adesão dos municípios ao sus, e particularmente seu ritmo no plano nacional, são explicados pela estratégia de descentralização do governo federal consubstanciada em portarias editadas pelo Ministério da Saúde. Os "arrancos" de adesão estão diretamente associados à edição de Normas Operacionais Básicas (NOB). A NOB/ 91 introduziu o princípio da habilitação ao sUS, mecanismo pelo qual os estados e municípios poderiam aderir à política federal de descentralização, subordinando-se às regras federais e capacitandose a receber as transferências oriundas daquele nível de governo. Entre 1991 e 1992, sob o Governo Collor, ocorreu um primeiro impulso de adesão, sob as NOB/91 e NOB/92, que regulamentavam a sistemática de transferências de recursos aos estados e municípios. Essas portarias ministeriais estabeleciam regras universais para as transferências de recursos, reduzindo assim o caráter incerto e politizado das transferências negociadas. Entretanto, essas NOBs receberam muitas críticas, principalmente por parte dos municípios, e foram "mais conhecidas pelo que não avançaram do que pelo que implantaram” (Guimarães, 2001, p. 49).

O segundo grande arranco, entre 1993 e 1995, ocorreu sob a vigência da NOB/93, durante o Governo Itamar Franco. Resultado de um amplo processo de consulta, esta Portaria do Ministério da Saúde abria um leque de escolhas aos municípios. O município poderia escolher entre três modalidades distintas de habilitação, de acordo com suas capacidades administrativas, e receberia recursos federais diretamente relacionados às funções de gestão assumidas. Nesse segundo momento, marcado pela incerteza quanto à capacidade de o Ministério da Saúde efetivamente realizar a integralidade das transferências em razão da escassez de recursos, cerca de 63\% dos municípios brasileiros aderiram ao sUs. 
O processo de municipalização completou-se sob a NOB/96, cuja implantação somente ocorreu a partir de 1998, no Governo Fernando Henrique Cardoso. A adesão dos municípios foi superior às metas do próprio Ministério da Saúde. Duas são as principais razões para este resultado. Em primeiro lugar, as novas regras para as transferências de recursos federais acrescentavam recursos aos cofres de $66 \%$ dos municípios brasileiros e eram fiscalmente neutras para 22\% (Costa et al., 1999, p. 45). Em segundo lugar, o Ministério da Saúde fez crer que as transferências seriam efetivamente realizadas.

Considerações finais

No início dos anos de 1990, quando já estavam consolidadas no Brasil as instituições federativas, os defensores do federalismo fiscal no Brasil acreditavam que a descentralização fiscal seria suficiente para que a descentralização de políticas sociais ocorresse. As evidências de que havia ocorrido descentralização do gasto social pareciam indicar que havia também ocorrido descentralização das políticas sociais (Médici, 1994). A análise da distribuição de competências revelava, contudo, que até meados dos anos de 1990, a descentralização efetiva tinha sido insuficiente, caótica ou mesmo inexistente (Almeida, 1995; Affonso e Silva, 1996).

As relações entre federalismo e descentralização das políticas sociais não são homogêneas entre os países federativos. Nos EUA, por exemplo, há uma corrida para baixo (race to the bottom) entre os estados no tocante à oferta de serviços sociais, pois estes temem atrair migrantes pobres caso ofereçam políticas sociais generosas. $\mathrm{O}$ fato de que o sistema fiscal norte-americano seja baixamente redistributivo - isto é, a capacidade fiscal dos estados repousa basicamente em seus próprios impostos - implica que elevação do gasto signifique elevação de impostos. Os estados norte-americanos competem entre si para atrair investimentos; e impostos elevados podem significar retração dos investimentos das empresas. Por esta razão, as políticas sociais dos governos estaduais são em geral financiadas por transferências do governo federal (Peterson \& Rom, 1990; Peterson, 1995).

Por outro lado, nos estados federativos em que a política social está no centro dos mecanismos de legitimação política dos governos, a competição entre os estados tende a implicar expansão da oferta de serviços sociais. A literatura comparada aponta que o interesse dos 
governos na visibilidade da responsabilidade pela oferta de benefícios sociais foi historicamente uma das razões de sua expansão. Pierson (1994) demonstrou que, no contexto de expansão do welfare state, a concentração da autoridade política implicava a concentração da accountability pela ampliação de benefícios. Banting (1995) demonstrou que no Canadá a disputa entre governo federal e províncias pelos créditos políticos derivados da ampliação de serviços sociais contribuiu para a expansão do welfare state canadense. Na União Européia - um novo arranjo federativo -, temia-se que a liberdade interna para o movimento dos capitais e da força-de-trabalho tivesse como resultado uma retração dos programas de proteção social, movimento este pelo qual - tal como nos EUA - países do norte (França, Alemanha, Bélgica) fossem forçados a aproximar-se dos baixos patamares de proteção social dos países do sul (Portugal, Espanha, Grécia). Na realidade, as evidências sugerem uma outra trajetória: os países do sul da Europa estão aumentando seus níveis de proteção efetiva, porque as políticas sociais estão no centro dos mecanismos de legitimação política dos Estados de Bem-Estar Social europeus.

No Brasil, as políticas sociais - entendidas como um compromisso dos governos com o bem-estar efetivo da população - não estão no centro dos mecanismos de legitimação política dos governos. Por esta razão, a descentralização dessas políticas não tende a ocorrer por uma disputa por créditos políticos entre os níveis de governo, mas de modo semelhante ao caso norte-americano - por indução do governo federal. Desse modo, a descentralização dessas políticas ocorreu quando o governo federal reuniu condições institucionais para formular e implementar programas de transferência de atribuiçóes para os governos locais.

Os governos José Sarney, Fernando Collor e Itamar Franco foram governos caracterizados por elevada instabilidade ministerial, isto é, por sucessivas e freqüentes trocas de ministros na área social. A instabilidade ministerial implicou alta rotatividade das burocracias encarregadas da formulação e implementação de políticas. Nessas condiçôes, o governo federal contava com baixa capacidade de iniciativa para adotar reformas, quaisquer que fossem elas.

Assim, embora a descentralização das políticas sociais estivesse no centro de suas respectivas agendas de reforma - com exceção do Governo Fernando Collor -, esses governos não tinham condiçôes institucionais para realizar as reformas que propunham. Em outras palavras, o caráter caótico, insuficiente ou inexistente da descentralização das políticas 
sociais até meados dos anos de 1990 foi menos resultado da oposição dos governos locais e mais expressão da incapacidade de implementação de políticas dos ministérios da área social.

No Governo Fernando Henrique Cardoso, a estabilidade e coesão das burocracias da área social permitiram que a agenda de descentralização fosse implementada, por meio de programas diversos de indução das decisóes dos governos locais. Aprovação de emendas à Constituição, portarias ministeriais, estabelecimento de exigências para a efetivação das transferências federais, desfinanciamento das empresas públicas são expressão de diferentes recursos e estratégias empregados pelo governo federal. Sua implementação revela que a capacidade de veto dos governos locais é bem mais reduzida do que supóe a teoria política sobre o federalismo.

\section{Recebido e aprovado em julho de 2002.}

\section{Notas}

1. Nos Estados Unidos, por exemplo, emendas à Constituição, mesmo que não afetem a distribuição federal de poderes, exigem a ratificação de 3/4 dos estados-membros e há mesmo tipos de emendas que não podem ser aprovados sem a ratificação de 49 dos 50 estados (Duchacek, 1970, p. 231).

2. Segundo decisões anteriores do Conselho Curador do FGTS, uma instância colegiada federal, os recursos do Fundo deveriam ser aplicados de modo que se destinassem $60 \%$ para habitação popular e $40 \%$ para as áreas de saneamento básico e infra-estrutura urbana. Cada unidade da federação deveria ter um orçamento anual, calculado com base na arrecadação líquida do Fundo e em critérios de distribuição entre os estados que atribuem pesos distintos às variáveis: arrecadação do FGTS, população urbana e déficit habitacional e de água e esgoto. Esse orçamento estabelece o valor máximo que pode ser emprestado para cada estado anualmente.

3. Entrevista com dirigente da $\mathrm{ABC}$ (Associação Brasileira de COHABs). As COHABs de Ceará, Alagoas, Rondônia, Rio Grande do Norte, Pernambuco, Espírito Santo, Mato Grosso e Goiás foram fechadas. A СОнав do Rio Grande do Sul havia declarado falência antes de 1995. As empresas estaduais de Bahia, Distrito Federal e Rio de Janeiro transformaramse em agências de desenvolvimento urbano.

4. A Emenda Calmon, regulamentada em 1985, já estabelecia a obrigatoriedade de estados, Distrito Federal e municípios investirem 25\% dos recursos provenientes da arrecadação de impostos na manutenção e no desenvolvimento do ensino.

5. As receitas de FPM, ICMS E IPI/EXP são automaticamente bloqueadas quando da realização dos créditos.

6. O art. 30 da Constituição de 1988 estabelece que o município é o único ente federado ao qual é atribuída a missão constitucional de prestar serviço de atendimento à saúde da população.

7. Pesquisas de opiniāo revelaram ser significativa a satisfação dos brasileiros com relação a esses serviços (Costa et al., 1999, p. 50). 
Referências bibliográficas

AFFONSO, R.; SILVA, P.L.B. (Org.). Descentralização e políticas sociais. São Paulo: FUNDAP, 1996.

ALMEIDA, M.H.T. Federalismo e políticas sociais. Revista Brasileira de Ciências Sociais. São Paulo, v. 28 n. 10, p. 88-108, 1995.

ARRETCHE, M. Estado federativo e politicas sociais: determinantes da descentralização. Rio de Janeiro: Revan, 2000.

BANTING, K.G. The welfare state as statecraft. In: LeIbfRIED, S.; PieRson, P. European social policy: between fragmentation and integration. Washington, DC: Brooking Institution, 1995.

COSTA, N.R.; SILVA, P.L.B.; RIBEIRO, J.M. A descentralização do sistema de saúde no Brasil. Revista do Serviço Público. Brasília, DF, 1999, v. 50, n. 3, p. 5-30, 1999.

D'ARCY, F.; BAENA DEL ALCAZAR, M. Décentralisation en France et en Espagne. Paris: Economica, 1986.

DUCHACEK, I. Comparative federalism: the territorial dimension of politics. Santa Barbara: Holt, Rinehart and Winston, 1970.

GUIMARÃES, L. Arquitetura da cooperação intergovernamental: os consórcios em saúde de Mato Grosso. 2001. 208f. Dissertação (Mestrado) - Escola Nacional de Saúde Pública, Fundação Oswaldo Cruz, Rio de Janeiro.

LIJPHART, A. Democracies: patterns of majoritarian and consensus government in twenty-one countries. New Haven: Yale University, 1984.

LIJPHART, A. Patterns of democracy: government forms and performance in thirty-six countries. New Haven: Yale University, 1999.

MÉDICI, A. A dinâmica do gasto social nas três esferas de governo: uma análise do período 1980-1992. São Paulo: FUNDAP/IESP, 1994. (Relatório de pesquisa do projeto Balanço e Perspectivas do Federalismo Fiscal no Brasil).

PETERSON, P.; ROM, M.C. Welfare magnets: a new case for a national standard. Washington, DC: Brookings Institution, 1990. 
PETERSON, P. The price of federalism. New York: The Tweentieth Century Fund, 1995.

PIERSON, P.; LEIBFRIED, S. The making of social policy. In: Leibfried, S.; Pierson, P. European social policy: between fragmentation and integration. Washington, DC: Brooking Institution, 1995.

PIERSON, P. Dismantling the welfare state? Reagan, Thatcher, and the politics of retrenchment. Cambridge: Cambridge University, 1994.

PINHEIRO, M.M.S. Fundos de poupança compulsória e financiamento da economia. Brasília, DF: IPEA, 1998. (Texto para discussão, n. 558)

PUTNAM, R.D. Comunidade e democracia: a experiência da Itália moderna. Rio de Janeiro: FGV, 1996.

RIKER, W. Federalism. In: Greenstein, F.; Polsby, N. (Ed.). Handbook of political science. Reading, Mass.: Addison-Wesley, 1975.

RIKER, W.H. The development of American federalism. Norwell: Kluwer Academic, 1987.

ROSANVALLON, P. Pouvoir local, pouvoirs locaux. Entrevista, p. 3946, out. 1993.

SEMEGHINI, U.C. FUNDEF: corrigindo distorções históricas. Brasília,DF, [199-?] (mimeo.).

SingER, A. Saúde. In: Lamounier, B.; Figueiredo, R. A era FHC: um balanço. São Paulo: Cultura Editores Associados, 2002.

TSEBELIS, G. Processo decisório em sistemas políticos: Veto players no presidencialismo, parlamentarismo, multicameralismo e pluripartidarismo. Revista Brasileira de Ciências Sociais. São Paulo, v. 12, n. 34, p. 89-117, jun. 1997.

WATTS, R.L. Comparing federal systems. Montreal: McGill-Queen's University, 1999.

WEAVER, K.R.; ROCKMAN, B. Do institutions matter? Washington, DC: Brookings Institution, 1993. 